\title{
Correction: Spelling Errors and Shouting Capitalization Lead to Additive Penalties to Trustworthiness of Online Health Information: Randomized Experiment With Laypersons
}

Harry J Witchel ${ }^{1}$, PhD; Georgina A Thompson ${ }^{1}$, BMBS; Christopher I Jones ${ }^{2}$, CSci, CStat, PhD; Carina E I Westling ${ }^{3}$, PhD; Juan Romero ${ }^{4}$; Alessia Nicotra ${ }^{4}$, MBBS, PhD, FRCP; Bruno Maag ${ }^{4}$, TGmeF, HFG; Hugo D Critchley ${ }^{1}$, MBChB, DPhil, FRCPsych

${ }^{1}$ Department of Neuroscience, Brighton and Sussex Medical School, Brighton, United Kingdom

${ }^{2}$ Department of Primary Care and Public Health, Brighton and Sussex Medical School, Brighton, United Kingdom

${ }^{3}$ Faculty of Media and Communication, Bournemouth University, Bournemouth, United Kingdom

${ }^{4}$ Dalton Maag Ltd, London, United Kingdom

Corresponding Author:

Harry J Witchel, PhD

Department of Neuroscience

Brighton and Sussex Medical School

Trafford Centre for Medical Research

Brighton,

United Kingdom

Phone: 441273873549

Email: h.witchel@bsms.ac.uk

\section{Related Article:}

Correction of: https://www.jmir.org/2020/6/e15171

(J Med Internet Res 2021;23(4):e29452) doi: 10.2196/29452

In "Spelling Errors and Shouting Capitalization Lead to Additive Penalties to Trustworthiness of Online Health Information: Randomized Experiment With Laypersons" (J Med Internet Res 2020;22(6):e15171) one error was noted after publication.

One reviewer of this paper, L Sbaffi, was listed twice in the originally published paper due to a system error. The duplicate instance of the reviewer's name has been removed from the corrected version.
The correction will appear in the online version of the paper on the JMIR Publications website on April 13, 2021, together with the publication of this correction notice. Because this was made after submission to PubMed, PubMed Central, and other full-text repositories, the corrected article has also been resubmitted to those repositories.

This is a non-peer-reviewed article. Submitted 07.04.21; accepted 07.04.21; published 13.04.21.

Please cite as:

Witchel HJ, Thompson GA, Jones CI, Westling CEI, Romero J, Nicotra A, Maag B, Critchley HD

Correction: Spelling Errors and Shouting Capitalization Lead to Additive Penalties to Trustworthiness of Online Health Information: Randomized Experiment With Laypersons

J Med Internet Res 2021;23(4):e29452

URL: https://www.jmir.org/2021/4/e29452

doi: $10.2196 / 29452$

PMID:

(CHarry J Witchel, Georgina A Thompson, Christopher I Jones, Carina E I Westling, Juan Romero, Alessia Nicotra, Bruno Maag, Hugo D Critchley. Originally published in the Journal of Medical Internet Research (http://www.jmir.org), 13.04.2021. This is an open-access article distributed under the terms of the Creative Commons Attribution License (https://creativecommons.org/licenses/by/4.0/), which permits unrestricted use, distribution, and reproduction in any medium, 
provided the original work, first published in the Journal of Medical Internet Research, is properly cited. The complete bibliographic information, a link to the original publication on http://www.jmir.org/, as well as this copyright and license information must be included. 